\title{
Engaging Distance Students: Ethical Inquiries
}

\author{
Sue Bridges, Judy Williams \\ University of Canterbury, New Zealand
}

\begin{abstract}
We report on an issue related to the distance delivery of Initial Teacher Education, with particular reference to EDIS723, a compulsory course on inquiry learning within the Graduate Diploma of Teaching and Learning (GradDipTchLn). A dilemma is posed by tensions between the need for ethical student research and the nature of inquiry as explored by students, particularly those who study by the Flexible Learning Option (FLO). The nature of inquiry learning and the requirements of EDIS723 are discussed. The ethical approval process carried out by the University of Canterbury Educational Research Human Ethics Committee (ERHEC) is examined, particularly in relation to the blanket approval' option which may be granted to courses or assignments. The problems posed by the lack of faceto-face interaction with FLO students, together with the online solutions which have been developed are outlined.
\end{abstract}

\section{Introduction}

The inquiry approach to learning, which places equal emphasis on the processes and products of learning and emphasises higher-order thinking [1] has increasingly been seen as a powerful way for schools to address education in the $21^{\text {st }}$ Century. This has been reflected in the development of the newlyimplemented New Zealand Curriculum (2010), which features organisation and delivery of the curriculum through the key competencies of: Thinking; Relating to others; Understanding languages; Symbols and texts; Managing self; and Participating and contributing [2]. Inquiry-based learning requires students to develop and explore essential and self-generated questions and wonderings through self-directed learning, which drives their meaningful and worthwhile learning experience [3].

\section{Research Background}

\subsection{EDIS723 course development}

From the turn of the $21^{\text {st }}$ Century, it became evident that the change in emphasis in the classroom from lower-order thinking skills such as remembering and knowing, to higher-order skills such as evaluating and creating [4] would necessitate a change in the preparation of teachers for the primary classroom [5]. In addition to this, primary classroom teachers in New Zealand (NZ) schools have traditionally enjoyed a greater degree of professional autonomy than exists in many other Western countries [6] and are expected to identify and teach to the individual learning needs of the children in their classrooms. However, at this time a common experience of students in initial teacher education did not reflect the role expected of them as New Zealand classroom teachers. Russell and Meek [6] visualised the subsequent situation as 'Crossing the professional divide', as shown in Figure 1.

\begin{tabular}{|c|c|}
\hline NZ Student teachers & NZ Teachers \\
\hline $\begin{array}{l}\text { Influences... } \\
\text { - High number of } \\
\text { short intensive } \\
\text { courses } \\
\text { - Simulated } \\
\text { assessment tasks } \\
\text { with reduced } \\
\text { complexity to } \\
\text { ensure adequate } \\
\text { reliability } \\
\text { Characteristics: } \\
\text { - Relatively } \\
\text { dependent learner } \\
\text { seeking guidelines } \\
\text { and criteria }\end{array}$ & $\begin{array}{l}\text { Influences... } \\
\text { - Open ended } \\
\text { description of } \\
\text { curriculum } \\
\text { - Absence of } \\
\text { externally driven } \\
\text { assessment for } \\
\text { 'accountability' } \\
\text {-Flexible use of } \\
\text { variety of } \\
\text { resources to } \\
\text { construct needs- } \\
\text { based programme } \\
\text { Characteristics: } \\
\text { - Highly self- } \\
\text { directed and } \\
\text { autonomous }\end{array}$ \\
\hline
\end{tabular}

Figure 1. Crossing the professional divide 
In recognition of these factors, during 2005 the Christchurch College of Education (CCE) developed an experiential inquiry-based learning course for the 15-month Graduate Diploma in Teaching and Learning (GradDipTchLn). Following the merger of CCE with the University of Canterbury (UC) in 2007, this course became the basis of EDIS723.

Students may study for the GradDipTchLn either on-campus or by distance through the flexible learning option (FLO). The teaching of the EDIS723 content (as distinct from the individual inquiries carried out by students) is carried out for on-campus students through weekly mentor-group meetings, supplemented by a series of mass lectures. The content of the mass lectures is made available to FLO students through Learn, the UC intranet for students. As the lectures are interactive in nature, with ongoing questions and answers encouraged during delivery, they are not recorded and placed on Learn as separate entities. Instead, the various elements and links to relevant websites are posted for FLO students to access as and when necessary.

The mentor group meetings consist of $12-15$ students with a lecturer-mentor, and focus on developing a community of learning through the students' mutual support of each others' inquiry journeys. FLO students do have a limited amount of face-to-face contact with course lecturer-mentors, but are much more reliant on blended learning approaches, including extensive use of Learn. They are, however, still required to 'attend' weekly mentor-group meetings, although in their case these occur online, using Learn. It is also very important for their understanding of the Inquiry Learning approach, that they develop a similar sense of belonging to a community of learning as the oncampus students do. As FLO students live in goegraphically diverse areas of the country, they usually cannot physically meet, and so again are reliant on the forums and facilities offered through Learn.

\subsection{Ethics}

Before the merger of CCE with UC, both UC and CCE maintained Human Ethics Committees. These committees played a similar role in their respective institutions. This was to ensure that studies which involved human participants were conducted in an ethical and safe manner. The CCE committee focused primarily on the post-graduate research work of the College. Academic approval for courses such as EDIS723 which involved students working within normal classroom settings, was a function of the Undergraduate Board of Studies. This body considered proposed assignments set within classrooms or likely to involve children as part of the process of granting approval, and separate ethical approval was not required. The judgment of lecturer- mentors, who were all staff members of the School of Primary Teacher Education (SPriTE) was considered a sufficient safeguard in the case of EDIS723.

Post-merger of CCE with $\mathrm{UC}$, the existing roles of the two Human Ethics Committees were revised. This was to avoid overlap and to make better use of existing expertise and resources. The CCE Human Ethics committee was renamed the Educational Research Human Ethics Committee (ERHEC) and situated within the new UC College of Education, in recognition of the time spent by Initial Teacher Education students in classrooms and the assignments that they were required to carry out in these and other educational settings. The need for many College of Education students to work with children and teaching staff in schools was recognised, as was the resulting impracticality of applying the existing model for granting ethical approval. As a consequence, a new blanket approval option was developed for low-risk activities likely to be carried out by Teacher Education students. This was developed during 2008 and came into force in 2009.

\section{Course requirements and nature of Inquiry Learning}

As is usual practice for all UC initial teacher education courses, each delivery occurrence of the course is evaluated and internally reviewed at its conclusion. In addition, EDIS723 also underwent indepth external peer-monitoring at the end of 2009. These processes resulted in a number of modifications, both substantial and minor, to improve quality and efficacy. The ethics blanket approval process was therefore applied to a refined version of inquiry-based learning designed as the 'best fit' for New Zealand primary teacher education students.

From the outset of their entry to the qualification, students are encouraged to consider aspects of education which vitally interest them and which they would like to follow-up in depth. These wonderings might arise from their curriculum studies, from their professional placements in schools, from their own experiences and observations of current education issues, or from any other relevant source.

Bridges and Gilmore [3] refer to the vital role that the course lecturer-mentors play in emphasising the modelling and demonstrating of pedagogy. The power of personal experience embedded in deep reflective practice, rather than potentially shallow vicarious learning, is viewed as essential. Major concepts introduced include the connection of deep thinking skills, and the potential of divergent thinking to work around the many inevitable 'roadblocks'. A roadblock is a term used in Inquiry learning to indicate any condition that makes it 
difficult to make progress or to achieve an objective. Roadblocks take many forms, and include obstacles which are foreseen, and those which occur as the inquiry proceeds. The terminology 'roadblock' implies a more flexible response on the part of the learner than other terms such as barrier or obstacle. A roadblock can be gone round or over - it does not necessarily involve a permanent stoppage. Responses to 'roadblocks' may include a change in the direction of the inquiry, or even an about turn. Any or all of these are acceptable, even expected, in Inquiry Learning. Inquiry is therefore shown as more fluid than traditional research, permitting changes in direction to accommodate new ideas, altered focuses, and timely serendipitous experiences. This is illustrated by the following reflection in one student's journal:

"Although roadblocks seemed like tedious, almost 'made-up' problems, they ended up being exciting turning points in our journey. These obstacles gave us options and opened up new ideas."

EDIS723 is a 16-credit course, meaning that students engage in a total of 160 hours directed and self-directed learning (10 hours of immersion over a 3 -week period, and 150 hours over the next 5-week block). They are required to attend and participate fully in all lectures and mentor group meetings, acting as contributors to each mini learning community. Whilst responsible for the learning focus of their own chosen inquiry, they are also responsible for actively supporting the learning journeys of their fellow mentees. The majority of the learning time is self-directed, thus demanding ethical practice to be independent and consistently adhered to. This is, however, monitored by lecturer-mentors.

Throughout the course, students fully document their learning journey in a journal designed individually to suit their inquiry topic and learning style. In addition to gathering information in their chosen area of interest, the journal is scaffolded to develop as a deeply reflective document.

During the final week, each student is required to formally share a 'gold nugget' aspect of their inquiry with peers and a wider audience. For on-campus students this takes the form of a mini-conference, while FLO students blend presentations face-to-face and on-line, to each other and to school-based audiences. FLO students are also required to post a contextual statement alongside their online presentation. This allows them to demonstrate the depth of their ethical commitment and application through their description of the processes undertaken in the course of their inquiry. All students are required to provide formal written feedback to a given number of peers, and also to receive feedback from their peers. They then develop a final reflective response to this feedback in their journals, prior to submission.

\section{The issue: tensions between ethical requirements and the nature of Inquiry Learning}

Ethical options and methods are fundamental to all research, in order to keep both participants and researchers safe. Institutions normally ensure that research carried out by their students is ethical by requiring ethical approval to be gained before the research is undertaken. Through this process issues with ethical implications are typically identified and addressed, and are not generally altered as the research progresses. If a change to the original terms of approval is required, the issue is referred back to the appropriate body for further consideration. However inquiry-based learning, while still requiring ethical procedures to be followed, is not expected to follow a pre-determined path and thus granting prior ethical approval for individual inquiries is difficult. The concept of 'roadblocks', as discussed earlier, shows this difference from a more traditional approach very clearly, and highlights the issue of ethical approval in relation to Inquiry Learning. In addition, inquiries may change direction several times, and as these changes often occur at very short notice. it is not practicable to refer all these changes to an Ethics Committee for approval. However, as with more traditional research paradigms, ethical thinking should be incorporated into all aspects of the process, from initiation to dissemination. In the case of EDIS723, this resulted in a tension between the requirements first of the CCE Human Ethics Committee and then of the UC ERHEC (postmerger) and the needs of the course. Initially, this tension seemed difficult to resolve, but the concept of a 'roadblock' (ie. seeing it as a temporary barrier, rather than a permanent obstacle), was applied to the issue and positive thinking employed. Fortuitously, by 2009, the UC ERHEC had developed the blanket approval option for low-risk activities likely to be carried out by Initial Teacher Education students. When this was investigated, it became clear that this was the option most likely to suit the case of EDIS723, although there were still outstanding issues that would need to be addressed. For instance, the lecturers responsible for other courses which gained ethical approval through the blanket approval option generally met requirements by setting assignments which were common to all students and for which issues could be pre-identified and addressed and this had become the norm for courses considered for blanket approval. This solution was not feasible for EDIS723 because the nature of inquiry-based learning requires each student to develop their own topic for the inquiry, and devise their own methods and approaches for exploring it. This involves a greater level of independent responsibility on the students' behalf than is 
normally found in tertiary-level assignments, and the course developers were unwilling to compromise this aspect of Inquiry Learning by applying the blanket approval in this form.

FLO students presented a further dilemma, because of their reliance on blended approaches, particularly e-learning. FLO students have only one half day of face-to-face interaction with their lecturer - mentors, which is taken at the outset of the course. Their weekly mentor group meetings take place online, whereas the on-campus students physically meet each week with their group and lecturermentor. During this time, and through the mass lectures, on-campus students could be given specific teaching relating to ethics, and their adherence to requirements could be monitored. Therefore, ensuring sufficient engagement and understanding of the ethics issue for FLO students was more difficult than for on-campus students because of the reduced amount of face-to-face contact available to them.

\section{The solution: addressing the issue for on-campus and FLO students}

An application for blanket ethical approval of EDIS723 was made in the second half of 2009. The application explained the unique nature of the course, and described the difficulty of the traditional approach to granting ethical approval because of the inherent unpredictability of inquiry-based learning. The need for greater delegation of ethical approval to the lecturer-mentors involved, and for placing greater responsibility on the students, was stressed. To cater for this, the application proposed that lecturermentors should have greater training in the process of granting ethical approval and that this training should be carried out where possible by a member of ERHEC. Lecturer-mentors would monitor each student's proposed inquiry topic, pointing out the ethical implications of strategies and approaches that might be used. Once the inquiry topic was approved, students would be required to notify their lecturermentor of any changes to their proposal. This requirement would largely be met through the existing requirement of the course that students must attend a weekly mentor group meeting, and also make individual contact weekly with their lecturermentor.

In addition to this monitoring, teaching specific to ethical issues and implications would be provided during the immersion phase of the course, which each student would be required to engage in. As a further indication that students were aware of and complied with these requirements, the format of the journal was extended to include an Ethics section. This would include copies of any consent forms, information sheets and other documents relating to ethics used by the students in the course of their inquiry. It would also include evidence in the form of diary entries or reflections of the student's awareness of the ethical implications of their study, the basis of their decisions regarding ethical issues and their subsequent actions.

These measures were accepted by ERHEC and blanket approval for EDIS723 was granted.

Implementation of these measures began in November 2009, with training sessions for lecturermentors, one of whom was already a member of ERHEC. These sessions were well received and lecturer-mentors felt confident that they had the more in-depth knowledge and understanding required to meet the greater responsibility required of them under the terms of the blanket approval.

For on-campus students, implementation of the requirements proved relatively straight-forward. One of the three face-to-face sessions for on-campus students was devoted to ethical principles and issues and covered the requirement for specific teaching to be carried out. This was supplemented by a further session in January 2010, taken by a member of ERHEC, which outlined the terms of the blanket approval granted to the course. Monitoring of ethical issues continued for the duration of EDIS723, and the Ethics section of the journals was also established. Lecturer-mentors were able to monitor the engagement of the students in their groups, and to intervene as and when necessary. It was also possible to check any changes to their inquiry within a very short time - an essential element, if the inquiry is to remain fluid and forward-moving. This model, as experienced by the on-campus students, was established as the 'norm', which the ERHEC recognised as meeting the terms and requirements of the blanket approval.

As expected. it proved more difficult to cater for the needs of the FLO students. Their course included a one day face-to-face session in January, but did not include the three face-to-face sessions given to the on-campus students in the previous November. In the past, these sessions had been covered by means of resources placed online on StudentNet, the intranet then in use in the CCE. An extra complication (or 'roadblock'!) was that as part of the changes made following the merger, StudentNet was phased out during the second half of 2009, to be replaced by Learn (Moodle). Learn then became the intranet to be used by the whole of the UC from Semester 1 2010. This meant that the online version of EDIS723 as used by previous cohorts through StudentNet had to be redeveloped, including a much more detailed section devoted to ethics than in the past. Staff had to develop their skills in the new Learn system prior to redeveloping each course for which they were responsible. Although support and training sessions were readily available, the reality was that many staff, including the authors, could not attend to these until lectures, exams and marking were concluded 
for the end of the academic year in late October / early November 2009. Coming as it did at a very busy time of year, followed by the long New Zealand summer break over December and January, together with the need for this issue to be resolved by the official course start date on $25^{\text {th }}$ January 2010, the work involved seemed daunting, to say the least. However, as always, the roadblock was successfully navigated and a new online version of EDIS723 was ready by mid-December 2009 .

It is always a challenge to ensure that distance students have engaged with online material, and often (as in the case of face-to-face students who may or may not attend lectures) it comes down to the willingness of the individual student to take responsibility for their learning [7] [8]. For many courses this is seen as almost a matter of choice for each student, but in the case of EDIS723 it was essential to find some way of ensuring that FLO students did engage with the ethical material, and for their lecturer-mentors to monitor this. Most of the old StudentNet resources were transferred to Learn in time for the FLO students to begin their immersion in inquiry in December, but the issue of ensuring students engaged in the ethical material had not been solved at this time.

Ironically, the development of the Learn site, which had provided a great deal of the pressure of work, also provided the solution to the issue of ensuring FLO students had engaged with the material. The Moodle software allowed reports to be generated which showed the activity of each student on the site. The potential of these reports to monitor whether or not students had accessed the ethics material was obvious, but the extent to which they had engaged with the material, rather than merely accessed it or viewed it was still unclear. Further investigation of the resources available on Learn identified the quiz tool as having potential here. The quiz tool was very flexible, with opportunities to select the type of question used and to give students feedback if they entered a wrong answer, as well as to set parameters around the accuracy of answers. A quiz was developed which required students to have accessed and read the material provided before they undertook the quiz.

Links to the following background material were posted in the Ethics section of the course website:

- ERHEC Guidelines, which provide a detailed outline of what is and is not expected to maintain a study in the low-risk category.

- New Zealand Education Institute (NZEI) Code of Ethics, which is the guiding document issued to all primary teachers. The NZEI is their union which provides both professional and employment-related support.
- $\quad$ Two PowerPoint presentations, prepared by lecturer-mentors to cover the specific teaching content required by ERHEC under the terms of the blanket approval granted by them.

Questions relating to these materials and to ethical awareness of common school-based situations were constructed. These took a range of forms, including open and forced-choice. The questions were:

- What are the five primary principles which underly the ERHEC Guidelines?

- What are the values related to the NZEI Code of Ethics?

- What are the main Operative Ethical Principles as identified in the Ethics PPT (Meek, 2009)?

- Do these situations require informed consent on the part of participants? Answer 'yes' or 'no' to each one (eg 1. yes 2.No etc)

1. Discussing work previously completed by children with their teacher.

2. Surveying children by means of an anonymous questionnaire.

3. Surveying teachers or other adults by means of an anonymous questionnaire.

4. Observing primary-aged children at work in a classroom setting to gather data for interpretation and presentation to a wider audience.

5. Discussing and/or observing a teacher's classroom practice with the aim of identifying and clarifying your own sense of 'Best Practice'.

- EDIS723 has been granted Blanket Approval according to the provisions given in the ERHEC Policy and Guidelines. As a result, what are your responsibilities?

Directions to where the correct answer could be found were provided as feedback for wrong answers. FLO students were required to undertake the quiz before being granted approval to continue with their inquiries, but it was strongly recommended that oncampus students also took the quiz. The quiz was further used as a catch-up task for any on-campus students who had missed the face-to-face ethics sessions. The lecturer-mentors then monitored which of their students had met the requirements through the activity reports. The activity reports included 
time and dates of each student's attempts at the quiz and their subsequent accessing of the material and resources related to questions they had got wrong.

Another means of monitoring student engagement was provided by the weekly 'check-in' reports submitted to lecturer-mentors by individual students. These often included a focus on ethical requirements, as is shown in the following extract from one such report:"Ethics Quiz: - Yes, found this useful to sort through the information and find the relevant points and not get so overwhelmed with it all. I have determined my needs in this area would be:

1: Consent form for Interview(s) with teacher at home school/other schools. Require signature from interviewee and will run this by you beforehand. 2. Disclosure information included in questionnaire for new entrant teachers I don't interview. This will include confidentiality (eg no names required).

I do have a question in regard to ethics requirements, however; When I have casual consversations with, (eg fellow students, parents at school gate) and I use this information to make generalised statements in my inquiry, do I have to inform them of my purpose of talking to them, use of info etc.,?" (FLO student, 2011)

Together, the quiz, the activity reports and the weekly check-in reports provided evidence of each student's engagement with the material.

\section{Results and discussion}

At the conclusion of the 2009/2010 course, four sources of information were investigated to provide a window into the efficacy of ethical procedures in the context of inquiry learning for this intake of graduate students. These included the checking of quiz and activity reports on the Learn site; an anonymous online course survey; lecturer-mentor feedback on the quality of ethical engagement and quality of work throughout the process; and observations of strategies taken to embrace or avoid various elements of ethical challenge in students' choices of inquiry focus and methodologies.

\subsection{Quiz and activity reports}

Activity logs indicated that all FLO students engaged with the Ethics materials and quiz as required. Although circumstances dictated that this became a 'just-in-time' resource, the reports show that this scaffolding appears to have been successful and relevant. In addition, approximately half of the on-campus students were similarly engaged, even though this was an optional activity for them.

The uptake has been similar as the current 2010/2011 course is underway. After only four days,
$80 \%$ of FLO students had already undertaken the quiz, with the remainder indicating their intention to do so within the week. On-campus students have also continued to engage in this additional optional (for them) activity.

\subsection{Online course survey}

Using a Likert scale of 1 (most negative) to 5 (most positive), students were asked to rate various aspects of the course and their inquiry-learning experience through it. Two questions were specifically focused on ethical elements:

Rate how well informed you felt about the UC ERHEC procedures and requirements

Rate how well you think you identified and met the ethical requirements of your inquiry.

Mean ratings were calculated for the on-campus and FLO subgroups (see Table 1), as well as for the complete sample. These findings are based on the 21 FLO students and 9 on-campus students who elected to complete the voluntary survey.

Table 1. Mean survey scores /5 for distance (FLO) and on-campus students

\begin{tabular}{|c|c|c|}
\hline Questions & FLO & On-campus \\
\hline $\begin{array}{c}\text { How well- } \\
\text { informed were } \\
\text { you? }\end{array}$ & 3.75 & 2.89 \\
$\begin{array}{c}\text { How well did } \\
\text { you identify } \\
\text { and meet } \\
\text { requirements? }\end{array}$ & 4.15 & 3.78 \\
\hline $\begin{array}{c}\text { Mean score } \\
\text { over all 8 } \\
\text { questions } \\
\text { Range of } \\
\text { scores }\end{array}$ & 3.62 & 3.42 \\
\hline
\end{tabular}

Three interesting patterns emerged. The first was that on average across the survey, FLO students registered higher ratings. Although the difference was not great, it was interesting because there is a general perception amongst lecturers in GradDipTchLn courses that distance students may be less positive about their course experience due to their limited face-to-face opportunities.

Secondly, FLO students indicated that they felt considerably better informed of ethical procedures $(\bar{x}=3.75)$ than on-campus students $(\bar{x}=2.89)$. This initially surprised the authors as we had presumed 
that the primary source information received by oncampus students directly from the ERHEC member would be perceived as more powerful than the secondary source information provided by the FLO lecturer-mentors, supplemented by the Learn site material and interactive quiz. It is likely that the scaffolding and direction given to FLO students, who are more skilled and experienced in making the most of blended learning opportunities than their oncampus peers, made more of a difference than we had anticipated.

The third finding was that all students rated their own ability to identify and meet ethical requirements more strongly than their ratings of being prepared for this. This was the top-scoring category for on campus students $(\bar{x}=3.78)$, and second-to-top for FLO $(\bar{x}=4.3)$. In reflecting on their experience from the endpoint, they felt empowered in the ethical decisions that they had made. As the survey was anonymous, there could be no personal advantage to them in inflating the response to impress those grading them.

\subsection{Lecturer-mentor feedback}

The journals show that FLO students engaged thoughtfully and ethically in their inquiry learning. Evidence of this was found in both their journal ethics sections, and in their contextual statements posted online alongside their online presentations. In particular they articulated a good understanding of the underlying concept of ethical procedures, which is to ensure that all participants operate in an open and trusting environment.

On-campus students demonstrated evidence through their ongoing mentor group discussions, and in their journals. In addition, some students discussed their ethical processes as part of their mini conference presentation.

Lecturer-mentors noted that while students reported low levels of confidence in addressing ethical issues at the start of the course, this concern had reduced noticeably by the end. They had taken advice regarding the need to avoid contentious or difficult issues within the relatively short time frame available, realising that this could not allow adequate time for negotiation of high-risk conditions through ERHEC. They understood the reasons why ethical practice is important, but did not allow these to become all-consuming at the expense of conducting sound and useful inquiries.

\subsection{Observations}

The additional ethical requirement had no effect on the quality of the work produced by this intake of students, whether FLO or on-campus, but did impact on the choices of inquiry topics in some cases. In the past, for example, students have included health- related focuses such as considering the transition between school, health-school and hospital for children undergoing cancer treatment. While ethical considerations had been paramount at that time, the time required to gain formal ethical approval had not been a necessary consideration and therefore did not present a barrier. Under the current requirements, the time constraints discourage such undertakings.

It occurred to the researchers that an interesting parallel can be drawn between this aspect of the students' experience with that of their lecturermentors whose role includes the juggling of active research with teaching and university service. The realities of the 'messy' world of academic life do not always fall easily into line with timelines of ethics committees, so a potential roadblock of a project perceived to be more risky, might be avoided by concentrating on less risky, but perhaps sometimes less useful research projects.

Methodologies were also modified by some students whose initial intention had been to collect data in the form of images of children, but who discovered that it was not always easy to gain permission from all relevant parties. Students also discovered the need to gain permission to use ideas gained through interview or professional conversation in their presentation. As ERHEC guidelines indicate that the form and use of such information should be approved by participants, some students felt that their inquiry outcomes were yet unshaped, and thus decided to avoid this potential 'roadblock'.

\subsection{Modelling of ethical practice}

An aspect of ethical practice which also plays an important part in shaping the students' future ethical awareness and decision- making as teachers, derives from those practices modelled by lecturer-mentors, and from the structures inherent in course design and delivery.

Lecturer-mentors not only engaged with the additional support and guidance of the ERHEC committee under the requirements of blanket approval of the EDIS723 course. They also came together as a community of practice on many levels in formal meetings, during casual conversations, through online forums and emails, and in other aspects of their teaching and research lives; discussing and exploring authentic examples of their own and their students' dealings with situations which require a level of ethical sensitivity. This is not altogether surprising in the world of teachers and teacher educators; both are caring professions in which the satisfaction of working effectively on an interpersonal level tends to surpass any financial imperatives. 
In all interactions with students, lecturer-mentors took care to explain and unpack the ethical dimensions inherent in the vast range of situations faced by teachers in their everyday professional lives. Students were able to, and did, ask questions and seek clarification regarding any situation they were unsure about - they were encouraged to take a slightly cautious approach and to check with lecturer-mentors rather than potentially create ethical dilemmas. In one way this might be seen as counterproductive to the inherent risk-taking and escaping of comfort zones usually regarded as important to inquiry-based learning. However, their increased sensitivity to the needs and rights of learners and of those who allow us the privilege to research some aspect of their lives, can, in the authors' view, only be seen as a good thing, Their thirst for exploration and inquiry was not tempered, but was gently guided by explicit ethical principles which were now more clearly apparent to them. The modeling provided by lecturer-mentors not only supported the students through their own journeys of inquiry, but also provided a model which they could adopt in their own practice when using inquiry-based learning approaches with children in the classroom.

While the course was carefully designed to allow ethical equity in the form of access and support to all students, whether they studied on- or off-campus, whether they were full- or part-time, some aspects of the institutional structure and administrative procedures were problematic in this dimension. Because the 10-hour immersion phase of the course is introduced in the term prior to the official start date of the 5-week course, students are ideally expected to familarise themselves with the course website structure and content in the intervening period. This allows maximisation of the opportunity to pursue an in-depth 5-week inquiry. Prior to the introduction of the new intranet, this was easy to achieve; using StudentNet (to which students had ongoing access), students simply logged on at their convenience during their Summer break. With the advent of the Learn Moodle intranet came the limitation that students would now gain access to the site only nine days prior to the official start date. They would also have to be fully enrolled to do so. Considerable negotiation with academic managers led to the relaxation of the nine-day access rule-ofthumb. This enabled fully-enrolled students (that is, the full-time students) to engage in a timely manner with the course material in general, and the ethics resources in particular. However, a complication arose for part-time students. The administrative requirement for these students was that they should enroll and pay for this course at the start of the academic year in which it was placed, unlike the fulltime students who did so at the outset of their entire course of study, some 12 months earlier. The consequence of this was that not only were part-time students difficult to identify in good time for an indepth immersion prior to the 5-week course, but also that until their enrolment had been processed by the university registry, they did not have access to this course, including the Learn site. Thus, equity of access, whilst maintained between on-campus and distance students, became unbalanced within the group of FLO (distance) students. Ethically this has been an uncomfortable situation for lecturer-mentors, who have then needed to provide considerable additional support to anxious students who find themselves less well-prepared than their peers, through no fault of their own. Ironically this demonstrates a level of unethical practice that students personally experience at the same time that they are asked to be ethically sensitive to other learners. Fortunately, further refinement of the course and administrative organisation in late 2011 will eliminate this difficulty for future cohorts of students taking this course. Yet another roadblock is being successfully tackled.

\section{Conclusions}

We have successfully found ways of resolving the tension between the need to follow ethical procedures and the fluid nature of inquiry learning. In particular, we have shown that despite a range of challenges, it is possible within a blended learning model to accommodate the greater autonomy, and therefore ethical responsibility, required of distance students engaged in inquiry learning. The online scaffolding, including the quiz, was a key component. However, the face-to-face element in the early stages, although limited, was of far greater importance for embedding ethics into the overall inquiry process than anticipated.

Both FLO and on-campus EDIS723 students are typically confused initially about the nature of inquiry learning, perhaps because of the knowledge of research they develop through studying to degree level prior to undertaking the GradDipTchLn. The face-to-face sessions played a large part in unpacking the different requirements of research and inquiry learning, which in turn gave FLO students in particular the necessary confidence to engage with the online material. However, the finding that all students felt more confident about their ability to follow ethical procedures in their inquiry and less confident that they were well informed may indicate that they relied to some extent on their prior knowledge.

This inquiry learning course has previously been offered only to students enrolled in the GradDipTchLn, but from 2011 all on-campus and FLO students enrolled in the Bachelor of Teaching and Learning (BTchLn) will be offered a similar course. The solutions to ethical issues developed for the GradDipTchLn will provide a useful model for 
these undergraduate students, but as they are not likely to have the same prior experience of research and gaining ethical approval, it may be necessary to scaffold their efforts more intensely. One vehicle for doing this could be to extend the contextual statement, currently required only of FLO students, to on-campus students. An unexpected outcome of the revised ethical procedures was that FLO students often used this statement to discuss what might be called their 'ethical journey', whereas on-campus students tended to use their peer presentations to cover the same aspect. The more structured approach incorporated in the contextual statement could provide the extra scaffolding likely to be required by undergraduate students.

So, did the students (particularly FLO students) understand and engage with the ethical requirements and responsibilities related to inquiry learning? We believe the answer is 'Yes'. Many students articulated a deep understanding of the purpose of the ethical requirements - they were not just 'ticking the boxes'. This was neatly expressed by one FLO student in his native Māori language. Ethical responsibility is ' kia pono me te tika ki te tangata $i$ nga wä katoa' - 'to be honest and transparent at all times'.

\section{References}

[1] Pohl, M., and Dixon, M. , Lift off to learning in inquiry-based classrooms. 2005, Victoria, Australia: Hawker Brownlow.

[2] Ministry of Education, The New Zealand Curriculum, Ministry Of Education, Editor. 2007, Learning Media: Wellington.

[3] Bridges, S. and F. Gilmore, Getting it Straight: The Difference between Inquiry-Based Learning and Teaching as Inquiry as Taught to Prospective Teachers. Waikato Journal of Education, 2010. 15(1): p. 79-96.

[4] Anderson, L., A revision of Bloom's taxonomy of educational objectives, in Flinders University School of Education. 1999: South Australia.

[5] Teachers Council, Guidelines for approval of teacher education programmes. 2005.

[6] Russell, S. and Meek, B. Implementing Inquiry Learning with Pre-Service Teachers: Walking the talk., in Improving University Teaching (INT) 31st International Conference. 2006: Dunedin, New Zealand.

[7] Moore, S., C. Armstrong, and J. Pearson, Lecture Absenteeism among Students in Higher Education: A Valuable Route to Understanding Student Motivation. Journal of Higher Education Policy and Management, 2008. 30(1): p. 15-24.
[8] Crawford, M. and C. Thomas-Maddox, Engaging the Students--Online. 2008 